\title{
"Salvar a la generación perdida": gubernamentalidad, empleabilidad y cultura del trabajo. El caso de un programa de empleo para jóvenes en Argentina
}

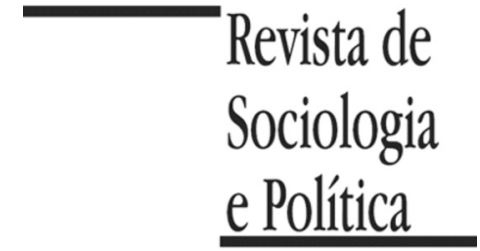

\author{
Gonzalo Assusa e María Gabriela Brandán Zehnder
}

\begin{abstract}
RESUMO
El propósito de nuestro artículo es analizar la manera en que operan las lógicas político-institucionales vinculadas a la gestión y producción del empleo juvenil, partiendo del supuesto que dichas intervenciones gubernamentales se estructuran a partir de la noción de empleabilidad, en tanto configuración de la cultura del trabajo. Para esto, abordamos el caso del Programa Jóvenes con Más y Mejor Trabajo (PJMyMT), implementado por el Ministerio de Trabajo, Empleo y Seguridad Social de la Nación (MTEySS), en Córdoba, Argentina. Para el cumplimento de nuestros objetivos, utilizamos una técnica cualitativa de recolección de datos a partir de entrevistas realizadas tanto a integrantes del equipo técnico del PJMyMT como a funcionarios del MTEySS, a lo largo de los años 2011 y 2012. Allí indagamos sobre las concepciones de éstos en torno al diagnóstico del desempleo juvenil, el lugar del Estado en su abordaje y el particular tipo de intervención que se propone desde la noción de empleabilidad, en el marco de las políticas activas de empleo. Utilizamos para la lectura de los datos obtenidos, la estrategia de análisis de contenido. El análisis realizado sobre la lógica político-institucional permitió dar cuenta tanto de los sentidos que construyen los agentes que lo implementan, como de las prácticas a las que el dispositivo da lugar. Así, una primera conclusión da cuenta que la "empleabilidad" es definida como objeto privilegiado de intervención de este programa estatal, dando lugar a instancias y servicios estructurados en torno a lógicas de rutinización y disciplinamiento orientadas a la producción de determinadas categorías de subjetividad para el trabajo. En este sentido, el PJMYMT se define en términos pedagógicos destinado fuertemente a la formación de disposiciones, hábitos y actitudes para el trabajo, antes que a una función estrictamente capacitadora. Así, la segunda conclusión es que esta lógica se inserta, tal como lo entendemos, como una intervención en la configuración de la "cultura del trabajo", en donde el discurso de la empleabilidad se estructrura en torno al valor del esfuerzo y se sostiene em un esquema en que la cultura del trabajo emerge como tradición y horizonte de significaciones, apareciendo como un campo eficaz de producción de legitimidad para las políticas públicas. Finalmente, entendemos que estos discursos aportan a la construcción de una lógica meritocrática como criterio de legitimación para la asignación de recursos estatales, proceso que puede leerse como la persistencia de una concepción voluntarista de las prácticas laborales y como un elemento residual de la cosmovisión neoliberal con la cual agentes y funcionarios pretenden polemizar.Los resultados de este artículo permiten abrir un campo de debate en el análisis de los dispositivos de inserción laboral juvenil al distanciarnos analíticamente de una mirada institucionalista de la implementación de programas gubernamentales para comprender los efectos de poder que éstas producen en sus beneficiarios.
\end{abstract}

PALAVRAS-CHAVE: trabajo; juventud; empleabilidad; gubernamentalidad; cultura del trabajo

Recebido em 16 de Dezembro de 2012. Aprovado em 20 de Fevereiro de 2013.

\section{Introducción}

A lo largo de los últimos diez años en Argentina, el trabajo recuperó su lugar como asunto central de gestión en diferentes instancias gubernamentales del país. Esto dio lugar a una proliferación de políticas y programas destinados a mejorar las condiciones laborales de aquellas personas 
${ }^{1}$ Los gobiernos del período postconvertibilidad en Argentina orientaron muchas de sus acciones a ubicar nuevamente al Estado como gestor central de los problemas del trabajo. Así, implementaron un conjunto amplio de políticas de trabajo que recorren desde marcos regulatorios hasta diálogo social, políticas de ingresos y de empleo, negociación colectiva, administración de conflictos, inspección de las condiciones de trabajo y protección social. Entre éstas destacamos, la elevación del Salario Mínimo Vital y Móvil, la sanción en 2004 de la Ley 25877 de Ordenamiento Laboral tendiente a reducir la flexibilización laboral de los años `90; la Promoción Colectiva que revitalizó las negociaciones entre las organizaciones de los trabajadores y las patronales; el Plan Nacional de Regularización del Trabajo orientado a la eliminación del trabajo no registrado y la puesta en marcha de una serie de políticas públicas activas de empleo en el marco del Plan Integral de Promoción de Empleo "Más y Mejor Trabajo".

${ }^{2}$ Nos referimos al problema en el sentido de que "la ocupación de la mano de obra comienza a considerarse en algún punto separado del proceso de producción, es decir se comprende que la problemática del desempleo posee complejas dimensiones que no pueden ser abordadas ya

exclusivamente a partir del incentivo a las empresas como puntapié para la incorporación de mano de obra" (Brandán Zehnder, Hernández \& Monte 2010, p. 5), en el marco de los modos de producción vigentes.

${ }^{3}$ Algunos análisis interesantes sobre las transformaciones en el mundo del trabajo a lo largo de la década del ` 90 pueden encontrarse en Grassi \& Danani (2009); Lindemboin (2008); Neffa (2009); Neffa \& Panigo (2009).

${ }^{4}$ Ver Avalle \& Brandán Zehnder (2011).

${ }^{5}$ El Plan Integral de Promoción del Empleo "Más y Mejor Trabajo" es el paraguas político bajo el cual se diseñan el resto de las políticas públicas orientadas al mejoramiento e inclusión laboral. que se encuentran ocupadas y a reintroducir en el mercado de trabajo a los grupos que permanecían en situación de desempleo. ${ }^{1}$

Estas acciones gubernamentales han sido contenidas en esquemas institucionales diferentes de los existentes en décadas anteriores, principalmente en lo referente al lugar asignado al Estado en relación al trabajo.

Como hemos sostenido en otras oportunidades, si bien el tratamiento del trabajo como "problema público"2 ganó terreno al promediar el fin de la década de los `90, no será hasta el inicio del nuevo siglo cuando las facultades de intervención del Estado en la esfera laboral irrumpen con toda su fuerza. ${ }^{3} \mathrm{El}$ "retorno de lo público" en el mundo del trabajo significó el tránsito del paradigma de la asistencia al de la promoción ${ }^{4}$ y supuso, no solamente una reconfiguración en relación a las instituciones del Estado sino que, además, importó una redefinición de los sujetos destinatarios.

De esta manera, tras la recuperación económica de Argentina a partir del año 2003 y la mejoría de los indicadores de ocupación, la acción estatal se orienta ya no a la asistencia de individuos que transitoriamente no pueden ingresar al mercado de trabajo, como fue durante los años `90; sino que apunta hacia la inclusión de aquellos grupos de la población que permanecen por largos períodos en situaciones de desocupación debido a características puntuales que los tornan "especialmente vulnerables".

Por otra parte, la acción del Estado se transforma ante estas nuevas poblaciones objetivo de intervención. Los espacios del Estado se acercan en alguna medida a estos grupos a partir de la constitución de una nueva institucionalidad enclavada en los diferentes territorios como instancias próximas de intervención. ${ }^{5}$

Así, la lógica político-institucional ${ }^{6}$ que caracteriza a los gobiernos del contexto post-convertibilidad inaugura una novedosa modalidad de gestión del trabajo/no-trabajo a partir de, por un lado, la identificación de poblacionesobjetivo $^{7}$ de intervención que suponen situaciones permanentes de desempleo; y por el otro, de la penetración de la gestión estatal del trabajo en el territorio orientada, ya no a generar situaciones de "salvataje" ante la desocupación, sino a construir una modalidad permanente y próxima que pretende redefinir la vinculación Estado/desocupados.

Uno de estos sectores poblacionales son los “jóvenes”, quienes son identificados desde la estatalidad como uno de los grupos con mayores dificultades a la hora de incorporarse al mundo laboral. La problemática específica de los jóvenes en el mercado de trabajo se retoma y reactualiza a partir de numerosas políticas estatales, siendo una de las más relevantes debido a su masividad y permanencia en el tiempo, el Programa Jóvenes con Más y Mejor Trabajo (en adelante, PJMYMT).

La idea sostenida en las próximas páginas pretende vincular las nuevas lógicas de intervención política sobre el trabajo a partir del análisis del PJMYMT, atendiendo a los discursos de los funcionarios que lo implemen$\tan ^{8}$. El supuesto que guía nuestra aproximación es que el Programa se configura en el marco de un diagnóstico de la problemática en términos de "cultura del trabajo" que da cuenta de la persistencia contradictoria de rasgos "residuales" junto a elementos "emergentes" de la práctica estatal respecto del trabajo", como herramienta de inclusión social y de ciudadanía. 
Éste posee cuatro ideas centrales, dentro de las cuales se destaca la territorialización de las políticas de trabajo. En este marco se crea una Red de Servicios Públicos de Empleo estructurado a partir de Oficinas de Empleo como espacios para tratar las problemáticas del trabajo, en el ámbito municipal. El supuesto que subyace a la creación de estas instancias es que la cercanía en el territorio del gobierno municipal es la mejor aproximación institucional a las problemáticas puntuales del mundo del trabajo de cada lugar.

${ }^{6}$ Por lógicas político-institucionales nos referimos a la racionalidad que opera tanto a nivel formal como informal en las instancias gubernamentales. Esta lógica tiene la característica principal de operar sobre la población homogeneizando y fragmentando a la vez, tal como sostiene Lazzarrato (2006, p. 13): "Estas gestiones diferenciadas de la desigualdad habilitan un amplio espectro de mecanismos mediante los cuales dispone sobre ese sub-conjunto de la población que son los desocupados, a los fines de localizarlos en función de sus particularidades (nivel de ingresos que perciben, educación, experiencias laborales previas) y poner en juego los diferentes niveles de desigualdad."
La noción de cultura del trabajo es problemática en varios sentidos. Incorporada en nuestra investigación como un fuerte emergente del campo, es recuperada aquí, en un sentido analítico, entendiéndola de manera diferente a como fue trabajada en cierta sociología y antropología del trabajo, es decir, como un "Conjunto de conocimientos teórico-prácticos, comportamientos, percepciones, actitudes y valores que los individuos adquieren y construyen a partir de su inserción en los procesos de trabajo y/o de la interiorización de la ideología sobre el trabajo [...]" (Palenzuela Palencia 1995, p. 13). Antes que como conjunto, aquí pensamos la «cultura del trabajo» como un campo y horizonte de significación, de intervención y disputa, que estructura la producción de sentidos, recursos y disposiciones en torno al mundo del trabajo, en donde se pone en juego la regulación de [1] la producción de categorías de subjetividades laborales de una población (Shore 2010, p. 36) y [2] la producción de legitimidad asociada al lugar estructurante del trabajo en la sociedad contemporánea ${ }^{10}$.

Este diagnóstico articula dos dimensiones que distinguiremos analíticamente. En la primera parte del texto analizaremos la lógica estatal de estas prácticas gubernamentales, o bien, la particular vinculación que propone y produce entre los beneficiarios de estas políticas y el Estado. Orientados por la categoría de gubernamentalidad abordaremos la formulación del PJMYMT como una «Política Activa» que, al mismo tiempo intenta 1) producir una forma singular de subjetividad a partir de su intervención en el mundo del trabajo con criterios de "ciudadanía / inclusión", y 2) generar una nueva trama institucional que se condice con el rol de promotor y orientador asumido por el Estado; institucionalidad que se instancia en configuraciones espaciales y en prácticas y formaciones burocráticas particulares.

En la segunda parte del texto identificaremos los elementos que constituyen la «empleabilidad» ${ }^{11}$ como objeto de intervención particular de esta política, definida en términos de "hábitos", "competencias interaccionales" y a la instalación del "esfuerzo" como valor de trabajo (tal como lo entendemos nosotros, objeto definido en torno a la producción de sujetos empleables). De esta manera, recuperaremos el diagnóstico en términos de "cultura del trabajo" orientados a dilucidar la racionalidad política que subyace esta forma de intervención en tanto de productora de legitimidad.

\section{Algunas notas en relación al Programa Jóvenes con Más y Mejor Trabajo}

\footnotetext{
${ }^{7}$ El concepto de "población" es ampliamente trabajado por Foucault $(2004,2009 ; 2010)$ para hacer referencia a ese conjunto de personas que en sí mismas no constituyen un sujeto político sino que, en el marco de una operatoria de gestión de la población, constituyen una categoría, un tipo de, una clasificación, sobre la cual se despliegan técnicas específicas de control y regulación de los cuerpos. Una dinámica de biopoder tendiente, en este análisis, a la reducción de las condiciones de inempleabilidad y, en consecuencia, de ese conjunto de población desempleada al tiempo
}

La lógica político-institucional como racionalidad propia del Estado, posee como herramientas privilegiadas de gestión de lo social, la ley y el aparato administrativo ${ }^{12}$. "A través de ellas, opera y se realiza la gestión del dinero y el capital, de poblaciones y mercancías y cosas y de espacios y lugares" (Ciuffolini \& Nuñez 2011, p. 24). Siguiendo este planteo, las políticas públicas son dispositivos centrales para esta lógica (junto a la ley y el aparato represivo -policial y legal- que asegura su cumplimiento), y por lo tanto, se constituyen en mecanismos de poder (Foucault 2009).

De esta manera, detenernos en el análisis del PJMYMT tiene por objeto indagar respecto de la manera en que estos dispositivos gubernamentales operan a los fines de producir efectos significativos sobre los sujetos ${ }^{13}$, en este caso, atendiendo a un diagnóstico que se estructura a partir de la "cultura del trabajo". Pese a que el mismo no aparece expresamente formulado de esta manera en la "letra" del Programa, una aproximación al discurso de los funcio- 
que desarrolla técnicas específicas de gobierno que fijan los límites, lo enunciable y lo posible de ser inscripto en una u otra posición, una "biopolítica" montada para administrar lo que es el trabajo, qué condiciones se requieren para él y quiénes acceden al mismo.

${ }^{8}$ Para este fin se trabajará con entrevistas realizadas durante los años 2011 y 2012 a funcionarios de la Gerencia de Empleo y Capacitación (Gecal) del Ministerio de Trabajo, Empleo y Seguridad Social de la Nación (MTEySS) y a miembros del Equipo Técnico de diferentes Oficinas de Empleo de la Ciudad de Córdoba, Argentina. Resulta significativo resaltar que no pretendemos con este análisis extender los resultados a otros contextos, sino que entendemos que el mismo se encuentra profundamente atravesado por las características donde se produce. Como herramienta metodológica utilizamos la técnica de análisis de contenido. La misma se constituye en una forma válida de abordaje de los dispositivos en tanto, "como señala Bardin (citado en Piñuel Raigada 2002) el análisis de contenido se convierte en una empresa de des-ocultación o re-velación de la expresión, donde ante todo interesa indagar sobre lo escondido, lo latente, lo no aparente, lo potencial, lo inédito (lo no dicho) de todo mensaje" (Piñuel Raigada 2002, p. 4).

${ }^{9}$ Tomamos los términos de "residual" y "emergente" que utiliza Williams (1977) para referir a aquellos rasgos que caracterizan a una cultura. Así, "Lo residual, por definición, ha sido formado efectivamente en el pasado, pero todavía se halla en actividad dentro del proceso cultural; no sólo -y a menudo ni eso- como un elemento del pasado sino como un elemento del presente.". Mientras que, "Por emergentes quiero significar, (...) los nuevos significados y valores, las nuevas prácticas, nuevas relaciones y tipos de relaciones que se crean continuamente" (idem, p. 144-145).

10 "Como los mitos, las políticas públicas ofrecen narrativas retóricas que sirven para justificar - o condenar- el presente, y algo más usual, para legitimar a quienes narios que lo implementan así como un análisis de su puesta en práctica, permiten vislumbrar otros sentidos.

El PJMYMT nace en el año 2008 en el marco general del Plan Integral para la Promoción del Empleo "Más y Mejor Trabajo", a cargo del MTEYSS. Este dispositivo se presenta como una respuesta ante la situación de desempleo de los jóvenes de entre 18 y 24 años de edad que presenten la característica de tener estudios secundarios incompletos. Así, el PJMYMT supone el diseño y desarrollo de un conjunto de instituciones estatales orientadas a la solución de estas dificultades y, además, el despliegue de acciones destinadas a la mejora de la empleabilidad y a la generación de oportunidades de inclusión social y laboral de los jóvenes.

Tal como lo menciona una de las resoluciones que componen su cuerpo normativo, el objeto principal del Programa es:

Generar oportunidades de inclusión social y laboral de las y los jóvenes a través de acciones integradas que les permitan identificar el perfil profesional en el cual deseen desempeñarse, finalizar su escolaridad obligatoria, realizar experiencias de formación y/o de prácticas calificantes en ambientes de trabajo, iniciar una actividad productiva de manera independiente o insertarse en un empleo. (Art. 1, Res. 497/2008)

Su gestión se apoya en las capacidades institucionales en el nivel local -particularmente de los municipios- por medio de los servicios de empleo. Incluye una asignación económica por beneficiario por un plazo que varía entre los 2 y los 18 meses condicionados al cumplimiento de compromisos específicos vinculados a la participación en actividades del programa.

Pese a que estas prestaciones se presentan de manera general, el acceso a una u otra estará mediada por la primera instancia del Programa: la orientación e inducción al mundo del trabajo:

Las prestaciones del PROGRAMA JOVENES CON MAS Y MEJOR TRABAJO serán diseñadas y ejecutadas a fin de servir de apoyo a la construcción e implementación del proyecto formativo y ocupacional que cada joven decida, con el objetivo de proporcionarles oportunidades de desarrollar trayectorias laborales pertinentes y de calidad, adecuadas a sus perfiles, a sus expectativas y a sus entornos. (Res. 461/2008)

Aquí se desprende un elemento que define la particularidad de este dispositivo en relación a otro tipo de intervenciones estatales orientadas a la inclusión laboral juvenil ${ }^{14}$ : el joven accederá a las diferentes prestaciones de acuerdo al proyecto formativo ocupacional decidido y definido por él mismo.

El Proyecto Formativo Ocupacional es una suerte de historia personal de cada uno de los beneficiarios que da cuenta de sus trayectorias educativas y formativas así como también de sus experiencias laborales previas. Este proyecto es individual y resume las herramientas con las cuales el joven cuenta para acceder al mercado de trabajo y aquellas que carece, y que debe obtener en el marco del programa. Si bien las prestaciones son generales y se presentan como acciones integradas, los recorridos que cada uno de los jóvenes emprende son particulares, generando, en términos del Programa diferentes "circuitos operativos" (Res. 461/2008). Este diseño individualizado tiene por objetivo que los jóvenes puedan acceder a oportunidades de desarrollar trayectorias laborales pertinentes y de calidad, adecuadas a sus perfiles, a sus expectativas y a sus entornos.

Tal como se advierte, la lógica político-institucional opera en un doble sentido. Por un lado totalizante -si bien no responde solamente al accionar estatal aunque este es uno de sus principales promotores- consistente en la incorporación al mundo del trabajo -y del consumo- de los jóvenes. Y, por otro lado, 
están en posiciones de autoridad establecidas" (Shore 2010, p. 32).

${ }^{11}$ La empleabilidad aparece desde una perspectiva polifacética que incluye diferentes tipos de aprendizajes significativos para la vida social y laboral (Jacinto 2008, p. 140). una operatoria al extremo individualizante que importa un seguimiento personalizado del individuo no incorporado al mundo laboral, a los efectos de mejorar sus condiciones y capacidades de empleabilidad.

Así, detenernos en la manera en que el Estado responde frente a situaciones que son definidas como "problemáticas", supone, por un lado, atender a las construcciones ideológicas que se disponen en relación a las mismas; y por el otro, dar cuenta de cómo estos sentidos que imprimen las políticas y programas se orientan a producir efectos determinados en los sujetos. Veremos a continuación cuáles son estas características que se les adscriben a los jóvenes a partir del PJMYMT y de qué manera las mismas son trasladadas al ámbito del trabajo, para luego profundizar respecto a las transformaciones que este Programa importa en tanto mecanismo de intervención gubernamental.

\section{La cuestión juvenil: repensando un relato de verdad}

12 “(...) el elemento que va a circular de los disciplinario a lo regularizador, que va a aplicarse del mismo modo al cuerpo y a la población, que permite a la vez controlar el orden disciplinario del cuerpo y los acontecimientos aleatorios de una multiplicidad biológica, el elemento que circula de uno a la otra, es la norma" (Foucault 2010, p. 208).

${ }^{13}$ En otras oportunidades señalamos que, "[d]urante años, los análisis politológicos respecto de las políticas públicas se han visto presos de dos perspectivas: aquella que analiza el proceso de elaboración de la política (diagnóstico de la problemática a la que da origen, análisis de los recursos, decisión) y los logros/dificultades de su implementación; o bien, aquella otra que hace énfasis en la gestión de la política pública propiamente dicha, en tanto repara en las fortalezas y debilidades de la administración pública para llevarla a cabo. Incluso, aquellos análisis que han pretendido incorporar a otros sectores de la sociedad civil al proceso decisional (teorías del empowerment y diseños participativos de las políticas públicas), no han sido capaces de construir una lectura alternativa al análisis de la política por la política misma. Es así que nuestra propuesta conceptual permite acercarnos a la lectura de las políticas públicas desde una mirada crítica que repare en sus efectos de poder" (Brandán Zehnder, De La Vega \& Hernández 2012, p. 105).
Para comprender la nueva configuración que se ha dado la estatalidad postconvertibilidad en relación a la gestión del empleo -en general-, y las dificultades juveniles para el trabajo -en particular-, resulta central atender a los "diagnósticos" que dan cuenta de las dificultades de este grupo poblacional en relación a su inserción laboral. Así, advertimos que la cuestión puntual de los jóvenes con el trabajo es construida "por fuera" del Estado mientras que luego es adoptada por sus agentes para dar cuenta de la "necesidad" de los dispositivos.

De esta manera, los funcionarios relatan cómo el PJMYMT responde a una necesidad "real" y "objetiva" y que lejos de ser una problemática local, afecta a diferentes países:
Generalmente el municipio que ya viene con una política, que viene trabajando con noso- tros toma muy bien a este programa porque casualmente, es una problemática que no la inventamos nosotros, que existe en todos los territorios este problema de la juventud. (F. Gecal 1, 22.dez.2011)
Con algunos informes de la OIT se comienza a detectar que hay una población que debe ser abordada porque, he, mal llamado porque a mi no me gusta llamarlos así, los ni, que ni buscan empleo ni tampoco estudian. Entonces se comienza a construir este programa, que es un programa que está destinado a jóvenes (F. Gecal 1, 22.dez.2011) ${ }^{15}$

Me parece bien que el Estado se involucre en esas cuestiones del tema del empleo por una cuestión de que, es un fenómeno mundial, el tema de los jóvenes ni-ni, ni estudian, ni trabajan. En ese sentido no es una problemática solo de Argentina, ni de córdoba, sino que es a nivel mundial, sobre todo los países sub desarrollados. (F. OE 1, 10.set.2012).

Tal como se desprende de los discursos de los funcionarios encargados del Programa, la problemática de los jóvenes con el trabajo no es algo que se "invente" sino que aparece como una "realidad objetiva" que debe ser abordada desde lo estatal. Se advierte la enunciación de un discurso que se construye a partir de diagnósticos que no son elaborados por las mismas instancias que implementan el programa sino que provienen de otros ámbitos diferentes del Estado, como el académico-científico y el de organizaciones internacionales (OIT, CEPAL, entre otras), en relación a las dificultades puntuales que enfrentan los jóvenes a la hora de conseguir trabajo.

Esta construcción de la "cuestión juvenil" (Salvia 2008) busca instalar una serie de problemas que no son comunes a todos los desocupados sino que son propias de este sector poblacional. Así, se construye un relato de verdad ${ }^{16}$ so- 
${ }^{14}$ Como bien reseña E. Rodríguez (2011), las respuestas estatales ante la problemática juvenil con el trabajo en la región latinoamericana han ido variando a lo largo del tiempo, en relación a los diagnósticos que se presentaban. Así, desde mediados de los `90 surgen una serie de políticas orientadas a lograr la inclusión laboral de este sector poblacional, que se desplazan en un arco que va desde programas destinados a fortalecer las competencias educativas (formales y profesionales), garantizar el primer empleo, fomentar el emprendedorismo, orientar e informar a los jóvenes en la búsqueda de trabajo, etc.

${ }^{15}$ Los códigos (F. Gecal 1, 22.dez.2011) corresponde a un código de entrevista creado por nosotros para respetar el anonimato de la fuente y que se compone de la categoría del entrevistado (F: funcionario), del lugar de la entrevista u organismo (ex.: Gecal), número de entrevista (1) y fecha de realización (22.12.11).

${ }^{16}$ El relato científico sobre la "cuestión juvenil" como un objeto con particularidades propias en relación a múltiples aspectos, entre estos el trabajo, es una de las aristas del "régimen de verdad" que circula en nuestras sociedades contemporáneas. Así, "Cada sociedad tiene su régimen de verdad, su "política general de la verdad": es decir, los tipos de discurso que ella acoge y hacen funcionar como verdaderos; los mecanismos y las instancias que permiten distinguir los enunciados verdaderos y los falsos, la manera de sancionar unos y otros; las técnicas y los procedimientos que son valorizados para la obtención de la verdad; el estatuto de aquellos encargados de decir qué es lo que funciona como verdadero". (Foucault 1992, p. 198). En el caso argentino, tal como da cuenta Jacinto (2010), hace ya más de 20 años que la problemática de los jóvenes con el mundo del trabajo es un terreno fértil de producción académica. "Así, los primeros abordajes se ocuparon de seguir la evolución de la desocupación juvenil a partir de los datos estadísticos disponibles, relacionándolas con los "factores individuales" asociados. Los condicionantes estructurales de esta situación bre las problemáticas de los jóvenes, que legitima al Programa como una estrategia central de gobierno.

De esta manera se advierte que la definición de los problemas sociales siempre implica una serie de supuestos sobre qué -o quién- constituye el verdadero problema, y por tanto, cuál puede ser su solución. Esta definición es política: depende de -y altera- la relación de fuerzas entre distintos "grupos sociales" (Martín Criado 2005, p. 87)

En este sentido, la juventud misma es el primer término en ser definido por los agentes estatales. Si bien hay una apropiación por parte de los funcionarios del supuesto generalizado que se sostiene respecto de las dificultades intrínsecas a la juventud para adquirir su primer trabajo, los funcionarios se alejan de esta noción, como un dato netamente generacional con características homogéneas, al recalcar el carácter fundamentalmente vulnerable de los jóvenes beneficiarios de este Programa:

(...) es un joven que está en situación de exclusión social. Esto ¿Qué significa? Que apunta a aquel joven que no ha concluido sus estudios secundarios. (F. Gecal 3, 22.dez.2011)

Los jóvenes, que otras cosas tienen los jóvenes, bueno, todos esos jóvenes que están en situación de exclusión social ¿Qué significa? Que de repente allí donde viven no hay condiciones mínimas ni de escuela, ni de salud, ni de dispensarios, este, lógicamente ahí está el nudo principal, con un gran problema, que a su vez tiene que ver con el tema de la droga. (F. Gecal 3, 22.dez.2011)

\begin{abstract}
No, no, no creo que sea un tema de jóvenes, porque, digamos, hay casos de jóvenes que terminan su secundario y están ahí, consiguen su, para mí es una cuestión de la vulnerabilidad pero...la vulnerabilidad en el sentido de que no son jóvenes que están preparados para asumir responsabilidades. Uno los ve, como que los ámbito familiares, o la postura que hay en los valores tradicionales, si se puede decir, o los contextos familiares, esas nuevas formas de familia que hay, es como que el joven no está preparado para esa sociedad (...) (F. OE 1, 10.set.2012)"
\end{abstract}

Los jóvenes vienen con toda la problemática los jóvenes, digamos, con drogas, con violencia familiar, vienen con muchas más cosas que con el problema del empleo ¿no? (F. Gecal 1, 22.dez.2011)

La vulnerabilidad social, que condena a situaciones de exclusión a individuos que participan del Programa es definida más allá del mundo del trabajo. Es decir, este grupo poblacional no sólo posee problemas de trabajo sino que los posee en tanto son jóvenes que provienen de situaciones de vulnerabilidad social. Problemáticas familiares, violencia, uso de drogas, carencia de estudios formales, son todos aspectos que caracterizan a esta juventud, de acuerdo a la mirada estatal. Los contextos de origen resultan problemáticos e impactan fuertemente en aquello que los funcionarios denominan "sentido de la responsabilidad" y que se vincula a un segundo aspecto que refiere a la juventud como categoría: la inmediatez.

Esta dimensión temporal de la juventud se relaciona con la carencia de "perspectiva de futuro", y por ende, con una actitud oportunista, la irresponsabilidad, la desorientación, el desgano:

(...) también hay un hábito construido en los jóvenes ¿no? Hay un hábito que está dado por al dinámica (...) hay todo un hábito que esta dado por la dinámica ¿no? estructural de los jóvenes, que está dado por la inmediatez. (...) por la inmediatez, por lo fragmentario de la experiencia, porque hay un poco, necesidad, o sea, a los jóvenes les cuesta mucho proyectarse a futuro (ET OE 5, 14.set.2012)

Generación de la juventud que tiene otros...que vive más el día a día, como te decía, que no puede pensar el futuro a largo plazo, vive más el día a día, como vive más disfruta el 
en el marco de las transformaciones y la crisis argentina en las últimas décadas han sido profusamente tratadas" (Jacinto 2010, p. 1) Sin embargo, hace algunos años algunos estudiosos han señalado la importancia de las dimensiones subjetivas en el análisis referidas a las aspiraciones y expectativas de los jóvenes $\mathrm{y}$, en este sentido, los abordajes han hecho énfasis en el análisis de períodos más largos y en las trayectorias laborales individuales, como elementos que permitirían comprender con más profundidad la complejidad del proceso de inserción laboral (Rosanvallon 2007; Jacinto 2010). día a día y por ahí, bueno, sale hasta la noche y se queda dormido ¿sí? (-) (ET OE 6, 14.set.2012)

(...) muchas de las características de la juventud tienen que ver con esto de no poder proyectarse hacia un futuro a mediano y a largo plazo, entonces, bueno, eso por un lado. (...) una forma, un hábito, que hace que todo sea momentáneo, todo pasajero, sumado a la (...) que la mayoría de los jóvenes tienen que no todos, pero si hay muchos jóvenes que están confundidos, que no saben lo que quieren. (ET OE 3, 12.set.2012)

El carácter fragmentario de sus trayectorias se asocia en el discurso de funcionarios, por un lado, a una etapa de la vida vinculada a experiencias del tipo "ensayo y error", donde los jóvenes eligen a partir de diferentes criterios, "sobre la marcha", es decir, donde no hay un plan a seguir en pos de alcanzar un objetivo futuro preestablecido por ellos. En el contexto del PJMYMT, esta noción se relaciona profundamente con el ámbito de lo laboral, es decir, con la "cultura del trabajo". Así, la inmediatez como característica temporal y la vulnerabilidad como condición de los beneficiarios del Programa se articulan para constituir la carencia de una serie de hábitos y valores identificados positivamente con el mundo del trabajo, tal como lo expresan diferentes entrevistados:

Son jóvenes que vienen de una...padres, de muchos padres que nunca han trabajado, de padres y abuelos que no han trabajado. Que no tienen esto como un valor. Que no lo ven al trabajo como algo dignificante (F. Gecal 1, 22.dez.2011)

\begin{abstract}
Uno los ve, como que los ámbito familiares, o la postura que hay en los valores tradicionales, si se puede decir, o los contextos familiares, esas nuevas formas de familia que hay, es como que el joven no está preparado para esa sociedad; o vienen muchos jóvenes de generaciones de desempleo estructural, o sea, ni los abuelos trabajaban, ni los padres. Entonces la única cultura, o el mundo del trabajo, como no son valores aprendidos, entonces hay jóvenes que no han visto ni laburar a sus viejos, entonces (...) si vos o ves un ritmo de vida que de lunes a viernes tu viejo se va en el auto o en el colectivo a laburar, o en la bici (...) es lógico cuando, digas, si vos tenés que ir a laburar digas: “ipor qué?; ¿Qué es eso?”, capaz que no, no comprendes el verbo trabajar. (F OE 1, 10.set.2012)

Se entiende que es una capacitación. En vez de hacerla en un curso, se hace en una empresa. Y es una capacitación. Los chicos te van a decir trabajo, yo te voy a decir trabajo de vez en cuando, la empresa te va a decir trabajás. Porque en un punto efectivamente trabajan porque se les pide que respeten horarios, que respeten, no, no faltar, que den aviso, que den un certificado, a modo de hábitos que tienen que incorporar. Porque si no, no dejan de sentirlo como una escuelita en donde están "jugando a...". Y no es "jugar a..." (ET OE 7, 26.dez.2011)
\end{abstract}

La cultura del trabajo es entendida desde la estatalidad en un doble sentido: por un lado, asociada a una serie de hábitos valorados positivamente en el mundo del trabajo; y por el otro, vinculada a una dimensión moral que subyace a esos hábitos, y que permite establecer una conexión entre "esfuerzo", "dignidad" y "legitimidad".

\section{El rol de la política activa: de la «cultura de la asistencia» a la «cultura del trabajo»}

Ahora bien, esta última dimensión que identificamos relacionada a la juventud, adquiere connotaciones más amplias en el contexto del PJMYMT ya que atraviesa la cuestión netamente laboral para situarla, además, en el espacio de la relación del Estado con los beneficiarios de los planes sociales. La falta de cultura del trabajo estaría asociada no sólo a condiciones estructurales, es decir, a una externalidad negativa de largos períodos de desocupación -donde los sujetos, debido a su desapego con el mundo laboral, no consiguen desarrollar hábitos e incorporar valores vinculados al mismo-; sino que además, la inexistencia de esa cultura del trabajo es percibida como una consecuencia directa de una "cultura de la dádiva estatal" para los sectores populares. 
${ }^{17}$ De manera sintética y tentativa definimos las "políticas activas como aquellas que con una perspectiva de mediano y largo plazo, y actuando al mismo tiempo sobre la oferta y la demanda de fuerza de trabajo, se proponen reducir el desempleo haciendo frente de manera durable a las causas macroeconómicas estructurales y además promover la generación de nuevos empleos". Por el contrario, "las políticas pasivas serían "las que prioritariamente ponen el acento en el comportamiento de la oferta de fuerza de trabajo, operan por lo general en el horizonte de la coyuntura o de ciclos cortos (aunque pueden dar lugar a efectos), proporcionan subsidios y políticas sociales a los desempleados y procuran contener el desempleo mediante el incremento de la población económicamente inactiva y la reducción de la oferta de fuerza de trabajo" (Neffa 2008, p. 319).

\footnotetext{
${ }^{18}$ De acuerdo a Neffa (2008) tras la crisis del año 2001, las estrategias para enfrentar los problemas de trabajo e ingresos se relacionan en mayor medida con la lucha contra la exclusión social y a favor de garantizar la gobernabilidad.
}

Ante situaciones de desempleo permanente en algunas familias, la "cultura del trabajo" como "valor" transmitido de generación en generación habría ido desapareciendo. Por ello, el Estado considera que debe tomar a su cargo un "rol educativo". Además, ese Estado ya no sería aquél que reforzaba esta ausencia a partir de la "dádiva" o la asistencia pasiva, sino que construiría sus intervenciones desde otro ángulo. En este sentido, el paradigma de las políticas activas $^{17}$ se presenta siempre en oposición a aquel propio de los años `90, de corte pasivo:

Bueno, porque toda política pasiva para mi es pensable desde un contexto de extrema
urgencia “ ¿si? Que a la población no hay nada para darle y hagamos que, digamos, si no
la gente se muere de hambre, que las condiciones no sean las más precarias, pero no es
sostenible en el tiempo ¿si? Porque uno genera todo esto que te decía, de la cultura, la no
cultura del trabajo, que es consecuencia de políticas pasivas durante mucho tiempo. (...)
Me refiero a un, digamos, a una asignación monetaria a cambio de nada ¿si? A eso me
refiero, a que se le da un subsidio. Y esto no sé que tan pasivo será, pero la idea es que,
por lo menos capacitar gente, por ahí no está trabajando pero al capacitarse ya entra den-
tro, ahora se entiende que es parte de...el trabajo. Trabajando de alguna forma, capacitan-
do para que (...) algún día a la sociedad...del trabajo. Entonces, bueno, ahí sería una
contraprestación (...) en sentido activo. (ET OE 3,12-09-12)

Así, la pérdida de la "cultura del trabajo" sería en alguna medida una herencia de las políticas asistencialistas de los años `90. El nuevo paradigma de políticas activas posiciona al Estado en un lugar diferente en relación a los problemas del empleo, que lo desplazan desde un modelo de Estado asistencialista hacia un modelo de Estado promotor:

\begin{abstract}
Yo creo que somos un actor fundamental. Ya no solamente regulamos, sino somos un actor activo dentro de la política de empleo. Tenemos una función de promover, función de garantizar, tenemos la función de articular básicamente. Yo creo que estamos haciendo los primeros pasos de un Estado activo ¿no? Que interviene cuando tiene que intervenir, que toma decisiones y demás. Y he estado en el período en el que estábamos más pasivos ¿no? Por eso, está cambiando. La verdad que yo siento que está cambiando nuestra mirada, de nuestro lugar en la sociedad. $\mathrm{Y}$ con este programa es fundamental. (F. Gecal 1, 22.dez.2011)
\end{abstract}

\begin{abstract}
El gran peligro de esto es que volvamos a un Estado en donde quiera ser Estado empresario, se meta en veinte cosas y después el Estado no tiene el capital necesario para sostenerlo y entonces pasa lo que pasaba (...). Entonces, digo, ni una, ni otra cosa, hay que buscar un punto de equilibrio. Fortalecimiento del Estado nuevamente, no ser un Estado empresario, sino un Estado que equilibra los, este, desajustes que hay en la sociedad. (F. Gecal 3, 22.dez.2011)
\end{abstract}

Así, el marco general que da lugar a las políticas activas como nuevo paradigma de intervención en la cuestión social, es una concepción de Estado que pretende alejarse tanto del paradigma intervencionista de los años `40, como de aquel Estado mínimo, netamente asistencialista, del menemismo de los ' 90 . El Estado en el proyecto político del período post-convertibilidad es un Estado que se define como promotor, garante, articulador y así también se pretende en relación a las problemáticas del trabajo. ${ }^{18}$

Resulta significativo señalar que los agentes estatales realizan una apropiación particular del sentido de las políticas activas que se aleja muchas veces de la conceptualización teórica de algunos analistas (Neffa 2012) en tanto diseño específico de políticas públicas, para vincularlas estrechamente a ese diagnóstico de la falta de cultura del trabajo.

Como hemos venido señalando, en el caso del Programa, esto importa una construcción alternativa de los sujetos a los que van destinadas las prestaciones y que encuentra su fundamento último en el "ideario" que sustenta las políticas activas, en las cuales: 
el sujeto, el participante de un programa tiene que buscar activamente empleo, digamos, activamente empleo con ayudas, con recursos, se acerca a las oficinas de empleo, o participa de distintos programas, pero en la medida que hace alguna actividad de mejora de la empleabilidad va a percibir ayudas económicas, incentivos o premios, va a cobrar más si hace más. (F. Gecal 2, 22.jun.2010)

El programa se enmarca en la línea de políticas activas, digamos, intenta profundizar eso, que el joven haga una actividad y que por hacer la actividad cobre un incentivo, o sea, digamos, eso es lo que significa digamos, es lo que uno busca es la autonomía del joven, digamos, y no la dependencia de un programa o de un beneficio, digamos, solamente, digamos, que se sostiene solamente por el beneficio, digamos, y que en realidad, que implica una actividad, digo, en sentido amplio, hacer una actividad implica la incorporación de valores, la incorporación de reglas, la incorporación de hábito de ir a trabajar, del hábito de estudiar, o sea, la posibilidad de generar relaciones, en ese sentido lo digo. (ET OE 6, 14.set.2012)

Tal como se advierte en los fragmentos, la política activa como herramienta central de gobierno tiene varios cometidos: por un lado, una suerte de función pedagógica respecto a determinados hábitos y valores "faltantes" en esta generación especialmente vulnerable e inmediata; y por el otro, instalar un nuevo modo de vinculación de esta generación respecto del Estado. La primera, que desarrollaremos en el próximo apartado, se orienta más hacia lo laboral. La segunda, refiere puntualmente a ese modo de gestionar lo social que podría referir en términos conceptuales a lo que se ha dado a llamar «gubernamentalidad». No obstante, ambas nociones se encuentran fundamentalmente imbricadas en el PJMYMT, y sólo son divididas aquí con propósitos analíticos.

\section{Gubernamentalidad: lo institucional visto desde sus mecanismos y sus efectos de poder}

${ }^{19}$ Tomamos aquí una de las acepciones que Foucault utiliza para referir la noción de gobierno. El segundo sentido que el autor utiliza para gobierno es aquel que refiere a la relación que uno puede establecer consigo mismo. Esto es lo que llamó el gobierno de sí y al que refirió toda la parte de su obra centrada fundamentalmente en la ética. Como señala Castro: "Foucault se interesa particularmente por la relación entre las formas de gobierno de sí y las de gobierno de los otros, y los modos de objetivación-subjetivación que se sitúan en el cruce de esos dos ejes" (Castro 2011, p. 176).
Al hablar de gubernamentalidad recuperamos a Foucault para referirnos al conjunto de instituciones, procedimientos, análisis y reflexiones, cálculos y tácticas orientados a ejercer esa forma específica de poder que supone inducir, desviar, facilitar o dificultar el campo posible de acciones de los otros. Así, el sentido de gobernar que queremos rescatar aquí es aquel que el autor define como un "conjunto de acciones sobre acciones posibles" (Foucault 1983, s.p. $)^{19}$.

Desde esta perspectiva, el PJMYMT como dispositivo de poder, se articula en un entramado más amplio de dispositivos a los fines de gestionar poblaciones de jóvenes desocupados para volverlos "sujetos empleables". En este sentido, el diseño institucional no es menor para la operatoria del dispositivo, sino que es parte del mismo y se imbrica en él.

No sólo se trata de una construcción del beneficiario joven con sus especificidades señaladas y traspoladas desde otros relatos que se vuelven "discursos de verdad", sino que, además, esta construcción encuentra sentido en el funcionamiento institucional propiamente dicho. De esta manera, los espacios del Estado y la burocracia adquieren nuevos sentidos a partir la puesta en juego de este dispositivo.

\section{Veamos estos aspectos:}

Digo, lo principal que es la oficina de empleo abierta como un lugar institucional donde puedan ir los desocupados de Córdoba a presentar su situación, inscribirse en la plataforma para encontrar alguna oportunidad de empleo, o puedan ser derivados a cursos de formación profesional, o también orientados para que hagan un micro emprendimiento u orientados a que terminen sus estudios, eso se está cumpliendo, se está afianzando, con distinta calidad, nivel (...) (F. Gecal 2, 22.jun.2010) 
Las oficinas de empleo buscan, son estos espacios, físicos les decimos nosotros, que en realidad prestan servicios de empleo ¿no? Y, y para nosotros es fundamental que esto exista antes para el programa porque es el lugar en donde va a ser atendido el joven ¿no? Entonces... el joven es una población especifica con características diferentes al resto de los desocupados. El joven, y más estos jóvenes que han tenido padres que por muchos años no han, no han desarrollado trabajos, por el país digamos, en que nos encontrábamos ¿no? Entonces debíamos generar en esas instancias que ya estaban creadas que eran las oficinas de empleo, espacios específicos y con personal con características que puedan comenzar a comprender la problemática de estos jóvenes ¿no? (F. Gecal 1, 22.dez.2011)

Las Oficinas de Empleo (OE) son el escenario central de la puesta en juego de este Programa. Si bien no corresponde exclusivamente a esta política, ya que opera como sede de diferentes prestaciones para desocupados y ocupados, no exclusivamente la población del PJMYMT, adquiere en el marco de éste una centralidad clave. Es que estos escenarios son el espacio físico donde los jóvenes desocupados asisten y mantienen una relación estrecha con los funcionarios y/o equipo técnico a cargo de la implementación del programa. Las OE son, en este sentido, las instancias territoriales más próximas de gestión de las poblaciones desocupadas.

En cuanto a lo que hemos llamado agentes estatales, nos referimos a todos aquellos funcionarios y/o equipo técnico que pone en marcha el Programa. Éstos son centrales en tanto que se contratan específicamente para este fin y no corresponden con la tradicional figura del "burócrata del planta" o el "arribista político". Sus perfiles corresponden (y así ellos mismos se definen) a profesionales de las ciencias sociales y jóvenes que, mayormente, han tenido experiencias de gestión pública o trabajo comunitario. Como señalan los entrevistados, constituyen un equipo específico, ya que son quienes mantienen un vínculo constante con los jóvenes:

Entramos en código y yo les explico siempre todo y trato de que ellos puedan ir construyendo esta confianza necesaria, porque es, cuando vos llegas a una oficina, a mi me ha pasado de hacer, de estar sin trabajo y he pasado de tener que hacer entrevistas que te preguntan hasta el color de la bombacha ¿viste? Y es fuerte. Entonces yo como que trato de construir ese vínculo de confianza y de calidez para, para que no sea tan así ¿no? Para que no se sientan invadidos ¿viste que vos te sentís?, le conté mi vida a alguien que no conozco, o sea. Entonces bueno, como que voy trabajando mucho eso y trato de que ellos se sientan cómodos y que vengan a la oficina, y cuando vienen, bueno, tomate un mate, hablamos. (ET OE 5, 14.set.2012)

Pero generalmente los chicos destacan que les gusta el trato, por ejemplo, siendo esto una dependencia municipal ellos destacan eso, que a todos los tratan bien, en otras partes de (...) no. Les gusta esto del tutor porque es personalizado, porque tratamos de ponerle muchas pilas a eso, a sostener la mirada cuando estamos viendo a un joven no de: "Si, en la compu y, si te escucho", y eso, la calidad y calidez humana en el trato con ellos. (ET OE 3, 12.set.2012)

Así, estos cuadros "burocráticos" establecen un lazo distintivo y personalizado con los jóvenes del PJMYMT. Alejados de la impersonalidad que supone el trato habitual con los agentes estatales, el Programa plantea un seguimiento individualizado de cada uno de sus participantes, a modo de acompañamiento pero también de control. Como hemos sostenido en otras oportunidades, "el acento en la promoción y en la capacidad de «agencia de los sujetos» puede traducirse, a su vez, en una mayor individualización de las prestaciones y de los resultados de las mismas. "El sujeto, así, deviene el centro desde el cual pensar las trayectorias de exclusión y, por ende, los mecanismos de inserción (...).” (Brandán Zehnder 2011, p. 7).

Esta característica propia de la política activa, supone entonces un contacto permanente y personalizado con la población destinataria del Programa que da 
cuenta de la operatoria de control que supone el mismo, y que se encuentra fundamentado en base a la idea de que las trayectorias de exclusión de cada uno de los jóvenes son específicas y así deben ser tratadas. En este sentido, resulta válido el planteo de Rosanvallon: "Si la eficacia de las políticas sociales impone considerar a los individuos en su singularidad, ¿no se corre el riesgo de transformar al Estado de Providencia en instancia de gestión y control de los comportamientos?" (Rosanvallon 2007, p. 202)

Ciertamente, como hemos señalado, la lógica político-institucional supone ambos elementos: por un lado la gestión de aquello que implica un elemento aleatorio y que importa una dificultad insalvable para la población como un todo (en este caso, los jóvenes desocupados); mientras que por el otro lado, los mecanismos operan a partir de la individualidad, solapándose con elementos disciplinarios. Veremos qué connotaciones particulares adquiere este argumento en los próximos apartados y cómo se vincula con esta dimensión "cultural" de la problemática del trabajo en los jóvenes, tendientes a producir de una singular manera el sujeto "empleable".

\section{La «empleabilidad» como objeto de intervención}

\footnotetext{
20 "Muchas acciones se fundamentaron en la concepción de que la baja empleabilidad de estos jóvenes estaba originada en su escaso capital humano (...). Se trataba de jóvenes provenientes de hogares pobres, que no alcanzaban a terminar la educación secundaria o aún la básica, que ocupaban los peores empleos en el sector informal, sin protección laboral y con bajos salarios y no lograban acumular experiencias acumulativas" (Jacinto 2008, p. 123).
}

En el marco de lo que venimos planteando en torno a la construcción de una nueva relación Estado-Beneficiarios, y a la definición de la problemática juvenil del empleo en términos de termporalidad y de vulnerabilidad, los agentes estatales definen la misión del programa como un cambio cultural, es decir, una transformación de la lógica de la acción de los jóvenes que reinstala el "esfuerzo" como valor central.

\begin{abstract}
No hay cultura, digamos, hablamos esto ayer, estoy en otro proyecto que tiene que ver también, es muy parecido al programa Jóvenes, y decía el vicepresidente de los metalúrgicos, que se ha perdido al cultura del trabajo, pero no en esta generación, hace tres o cuatro generaciones que no hay cultura de trabajo. Entonces también hay un background, podríamos decir, con el día a día que dice que el esfuerzo no vale nada, que hace tres generaciones que veo a mis padres, mis abuelos, mis bisabuelos que no trabajaron, entonces que, que traigo de mi casa también y lo exteriorizo (ET OE 3, 12.set.2012)
\end{abstract}

En el discurso de funcionarios del ministerio y de las oficinas de empleo encontramos una fuerte referencia a una carencia en términos de "cultura del trabajo", de prácticas rutinizadas y valores asociados al esfuerzo como criterio válido de asignación de recursos. En relación a la definición de la juventud vinculada a esta falta, el programa construye su espacio de intervención en términos de empleabilidad ${ }^{20}$. Tal como plantea Jardim,

[...] Jos jovens entrevistados buscam corresponder, no esforço de constituição de sua empregabilidade -permanecendo na escola, realizando cursos profi ssionais, acumulando experiências, etc. -, há também uma implicação ético-subjetiva, em que se procura corresponder às expectativas menos evidentes, mas ainda assim circulantes nos discursos de recursos humanos: tratam-se quase de modos de ser, de sentir e de pensar (Jardim 2011, p. 501).

La empleabilidad aparece como un conjunto de disposiciones para el trabajo, de competencias y saberes prácticos, técnicos, comunicacionales y actitudinales (Jacinto \& Millenaar 2012, p. 144). Estas disposiciones se piensan como eminentemente subjetivas, formadas en trayectorias familiares y escolares que, en el caso de la población aquí analizada, presentan, según el diagnóstico del ministerio, un momento de crisis y discontinuidad en la década del noventa y, por medio de los padres-adultos, se traslada a la actual generación de jóvenes (ingresantes al mercado de trabajo). 
${ }^{21}$ Intentamos operar de la misma manera en la que Merklen analiza la "alquimia al revés" que, durante los años `90, implicó transformar la politicidad de los sectores populares desde los sujetos "trabajadores" hacia los sujetos "pobres" (Merklen 2005). La orientación de esta producción subjetiva sería, si se quiere, contraria en nuestro caso.
Una de las ideas rectoras de nuestro trabajo es que este diagnóstico proporcionado por instancias políticas y científicas produce, aunque no de manera unilineal, las condiciones de una subjetividad laboral de su propia poblaciónobjetivo, es decir, produce a este grupo como jóvenes in-empleables ${ }^{21}$. En otras palabras, decimos que "[...] uno de los aspectos más importantes de la formulación de políticas públicas es la forma en que las políticas construyen nuevas categorías de subjetividad" (Shore 2010, p. 36), o bien, reconstituyen configuraciones subjetivas consideradas tan necesarias como perdidas.

VI.1 Experiencias, formas de interacción y formación de hábitos

Una serie de instancias institucionalmente definidas (las denominadas "prestaciones") apuntan a la creación, reconocimiento y revalorización de saberes adquiridos o consolidados, a revertir experiencias y trayectorias previas sin "calificación" y sin empleos "registrados". En este marco podemos encontrar la denominada Certificación de Estudios Formales (CEF) o Formación Profesional (FP).

[...] logran reflexionar, y lo primero que se les enseña es que cuando dicen yo no sé hacer nada, lo primero que le enseña el tutor, el profesor y quien está a cargo, es que él sabe. Sabe cuidar al hermanito, hasta construir la casa que le ayudo a construir al padre, tiene potencialidades. [...] descubrir que él como persona tiene ambiciones. Que tiene muchas, sin duda, debilidades, pero que tiene... (F. Gecal 3, 22.dez.2011).

Esta revalorización no se plantea en términos exclusivamente "productivos" -en el sentido económico-, sino fundamentalmente a partir de aquellos saberes, competencias y hábitos que, desde este discurso, se consideran positivos en términos sociales y políticos, y que aportan a la función integradora del trabajo: a la inclusión social.

El denominado Proceso de Orientación e Inducción al Mundo del Trabajo (POI) se ve conectado a esta problemática, aunque de otra manera. La forma en la que los agentes entienden el aporte de este servicio al mejoramiento de la empleabilidad de los jóvenes, orienta su sentido hacia la formación de una experiencia institucional mucho más estable y regulada que la que estos jóvenes en situación de vulnerabilidad efectivamente habrían tenido. Esta instancia pretende rutinizar sus prácticas, entrenarlos, prepararlos para el mercado de trabajo que les toca.

$\mathrm{Y}$, en realidad es como que, el... el nivel, digamos, como de exigencia no es bajo, sabiendo como por ahí son las experiencias anteriores de los jóvenes. Hay un curso anterior que es el POI [...] y ellos tienen como una tutora, pero digamos, de un viernes a un lunes el joven tiene que empezar a llegar a horario, el joven tiene que empezar a bañarse todas las mañanas, el joven tiene que empezar a habituarse a no llegar tarde, entonces, bueno, tiene que ser como una persona que claramente pueda sostener porque si no se genera como una sensación, en la persona, en el empleador, en el equipo... entonces, bueno, y eso es muy difícil de verlo, digamos, por más que uno pueda hacer una entrevista y un seguimiento ahí en el espacio del POI, que es el curso, viniera todos los días en mi horario, que se yo, pero porque ese espacio es como más educativo y entre iguales se sentía cómodo y bueno [...] a un lugar de trabajo donde tiene todos compañeros de 30 años y es una cosa, y entra a las 6 de la mañana y bueno... (ET OE 4, 14.set.2012)

${ }^{22}$ De igual manera, a nuestro entender, todo el programa funciona como instancia "formativa", aunque no necesariamente en el sentido de "capacitación". Es decir, "educa", en un sentido amplio
Por último, el denominado Entrenamiento para el Trabajo se entiende, también, como una instancia fundamentalmente educativa ${ }^{22}$, de formación de competencias laborales que no se restringen exclusivamente a habilidades técnicas, sino que hacen mella en el desarrollo de ciertas capacidades interaccionales que, a partir del diagnóstico que define los problemas de la población objetivo del programa, son parte fundamental de su déficit. 
vinculado a la formación de hábitos, de disposiciones, de formas de comportarse, más que en el desarrollo de competencias técnicas. En el caso de los "Entrenamientos", el acento educativo se utiliza para distinguirlo de la generación de "empleo genuino". El equipo técnico muchas veces utiliza este énfasis para aclarar que el programa no "inserta" laboralmente, no ubica en un puesto, sino que "mejora la empleabilidad".

${ }^{23}$ En relación a lo ya planteado respecto del carácter "educativo", este vínculo homólogo entre relaciones de autoridad en el espacio escolar y en el espacio laboral está vinculado directamente al diagnóstico de des-institucionalizacion como causante de la falta de hábito y rutinización, portado por los agentes del programa. El esquema que opera en nuestro caso es similar al de un entrevistado de un centro de capacitación en el estudio de Jacinto y Millenaar "Lo que les falta a estos chicos hoy es personas que los guíen con firmeza. Se perdió el valor de la organización, del respeto por la autoridad [...] La apuesta está en la capacidad de construir, elegir la vida que uno quiere y no en la cultura de la queja" (Jacinto \& Millenaar 2009, p. 85)
Por lo que pudimos observar respecto de la práctica y los discursos de los agentes del programa, la intervención en el ámbito de la empleabilidad entendida como "cambio cultural", esto es, en términos de una ruptura y una discontinuidad respecto de lo que venía siendo la trayectoria familiar e individual de estos jóvenes vulnerables, un elemento central de este complejo problema es la cuestión del hábito. Buena parte de las competencias laborales que intentan formarse en los entrenamientos y en el POI están fundadas en prácticas cotidianas, rutinarias, tales como llegar a horario, no faltar, o bien, ante una urgencia, dar aviso anticipado de la falta. Ante el supuesto de experiencias radicalmente des-institucionalizadas (relacionado con la idea de crisis moral vinculada a la crisis de las instituciones como la escuela y la familia) estas rutinas cotidianas habrían desaparecido.

Problemas con los empresarios hemos tenido... pero realmente yo pensé que íbamos a
tener... es difícil llegar al empresario, pero después cuando el joven incorpora, a veces
cuando, tenemos más problemas con el joven que con un empresario, porque por ejemplo
el joven no tiene hábito. El joven viene ¿no? De no ir ni al colegio, por lo tanto no sabe ni
cumplir ni un horario. Entonces a veces nos cuesta mantenerlo al joven yendo todos los
días, cuatro horas, que cumpla con reglamentos, que cum... que empiece a recibir órde-
nes de otro, que a veces tenemos que contener mucho al joven. También ahí al empresa-
rio, "por favor usted, estamos trabajando por un joven que no tiene el hábito, justamente
lo está incorporando", digamos (F Gecal 1,22.dez.2011).

A su vez, esta desinstitucionalización y la pérdida de las prácticas cotidianas formativas, habrían generado, desde la perspectiva de estos agentes, una serie de problemas en torno al reconocimiento de la autoridad (del "jefe" o el "encargado" de los espacios laborales), esto es, al reconocimiento de una cadena de mando en el ámbito de trabajo que, en trayectorias "normales", se establecería en forma de una homología a la relación de autoridad escolar con el docente. ${ }^{23}$

Nociones como la de "entrenamiento", con un tono fuertemente pedagógico, son interpretadas, en el marco de las tareas de estos agentes y de la intervención estatal, como parte de la construcción de competencias en torno a la "responsabilidad", puesta en cuestión permanentemente en la problemática de la ausencia en el lugar de trabajo. En este ámbito se incluyen temáticas como el aprendizaje de las razones válidas y no-válidas para faltar, la necesidad de dar aviso ante una inminente ausencia, etc.

\begin{abstract}
Si, depende de las particularidades, no, o sea, más allá de la cuestión económica, digamos, si veo que, como que nosotros, lo que pasa es que nosotros al tener la primera instancia de capacitación, del POI, donde los chicos tienen que cumplir horarios, tienen que asistir, todo, es como que vuelven a estar dentro de un margen institucional que tienen que cumplir horarios, cumplir asistencias, entonces, cuando uno ya los deriva a la práctica, si bien, si faltan, a veces no avisan, sobre todo en las prácticas... pero no es la gran mayoría. Están como reglamentados, que tienen que avisar, que tienen que respetar a la persona que tienen en la empresa, que no tienen que faltar... entonces como que no se da tanto (ET OE 1, 12.set.2012)

Y el planteo es, bueno, un joven; tenés dos casos, el positivo que sí, es cumplidor, trabajador, el negativo es joven que se ausenta, que se distrae, que habla por teléfono, no tiene, no está motivado para laburar (ET OE 9, 16.dez.2011).
\end{abstract}

Por otra parte, en consonancia con la definición del ámbito de empleabilidad como desarrollo subjetivo o personal, muchos de los problemas de empleo de los jóvenes del programa son interpretados en términos de "desmotivación", "falta de autoestima" y de afectación de las experiencias laborales inestables al desarrollo personal. En este sentido, el programa intenta elaborar competencias de interacción vinculadas al momento de la entrevista 
laboral, tales como la "presentación de sî", la "seguridad", y la capacidad de "venderse".

\begin{abstract}
Mostrarse, venderse. No saben vender, no saben mostrarse, mucha... como... vergüenza. Hay otros casos ¿no? Pero yo te digo como la generalidad. A la hora de presentarse, cuando vos le conseguís el trabajo, estamos teniendo un montón de dificultades, digamos, con el hábito de la responsabilidad. Llegar temprano, llegar a horario. Tenemos un montón de problemas que decís, el horario de trabajo empieza a las ocho...ocho y cuarto; ocho y media: "No, que el colectivo", y bueno, si vos ves que llegas tarde una hora, levantate a las seis y media, levantate a las siete... y llega a las ocho (F OE 1, 10.set.2012).
\end{abstract}

Es así que este dispositivo construye como uno de sus principales ámbitos de intervención un campo de "conductas" y "formalidades", que espera ser modificado a partir de un cambio -fundamentalmente- cultural (en relación con el lugar del Estado respecto de la problemática del empleo y de la definición de la juventud en su dimensión de temporalidad y vulnerabilidad) y que atraviesan la cuestión del empleo juvenil mucho más allá de las competencias de tipo técnico: conductas como bañarse todas las mañanas, mirar a los ojos al hablar, etc.

Bueno, la primera, que por ahí de alguna manera como que...vimos, más allá de la tarea en sí que uno va a cumplir, es todo lo que tiene que ver, digamos, lo que envuelve esa tarea, o sea, el horario, la forma de comunicarse con el jefe, el tener que, como aprehender, con $\mathrm{H}$, digamos, determinadas conductas o por ahí formalidades, o sea, estas cosas de si me enfermo, la única manera de faltar justificadamente es tener un certificado. Y bueno, también pensando en lo que a ellos se les complica conseguir un certificado médico, que en el dispensario del barrio no hay ¿no? Pero eso yo noté muy fuerte, no era, nunca tuve un problema de: "No labura, no se mueve o no hace", sino lo otro: "Llega tarde, no se puede relacionar con los compañeros, coquetea con una mujer", ese tipo de cosas digamos (ET OE 4, 14.set.2012).

VI.2 Esfuerzo y legitimidad

${ }^{24}$ En el análisis de Jacinto y Millenaar sobre centros de capacitación aparecen oposiciones homólogas: "Pero en esta institución se plantean incidir en un aspecto más amplio respecto al trabajo, sosteniendo que promueven la «cultura del trabajo», que se ha visto fuertemente afectada tanto por el desempleo como por la irrupción masiva de planes sociales" (Jacinto \& Millenaar 2009, p. 82)
A partir de esto, entendemos que podemos establecer una fuerte conexión entre el lugar que estos agentes le asignan al Estado en relación con el problema del empleo, la construcción de la juventud como objeto de intervención en términos de problema cultural (actitudinal, de rutina, de inestabilidad y falta de planificación, etc.), y por último, la construcción de la empleabilidad como espacio de intervención fundamentalmente conductual, comunicacional y de formación de hábitos. Ahora bien, ¿Qué contenidos morales son los que específicamente se ponen en juego en las prestaciones del PJMYMT?

Tal como lo entendemos, la cuestión del esfuerzo se instala en el centro de la intervención y del discurso de los agentes, a la vez que define el signo que muchos de los mismos pretenderían imprimirle al programa distinguiéndolo de los antiguos "planes sociales" 24 .

Por lo cual, no era de aplicación masiva, o sea, pasábamos de algo masivo que contribuyó a cierta paz social en su momento, y que después se fue haciendo obsoleto porque la ayuda económica se fue, digamos, diluyendo el aporte y además se empezó a hablar también de un cambio de políticas pasivas a políticas activas. Que hoy son políticas activas de empleo donde el sujeto, el participante de un programa, tiene que buscar activamente empleo, digamos, activamente empleo con ayudas, con recursos, se acerca a las oficinas de empleo, o participa de distintos programas, pero en la medida que hace alguna actividad de mejora de la empleabilidad va a percibir ayudas económicas, incentivos o premios, va a cobrar más si hace más (F. Gecal 2, 22.jun.2010).

Lo ya planteado acerca de la definición de las políticas activas, funciona en referencia al beneficiario como un elemento distintivo, fundamentalmente en 
${ }^{25}$ En el mismo sentido, una de las etnografías económicas de Wilkis y Carenzo analiza cómo vendedores de una revista realizada para la comercialización por parte de desempleados y "personas en situación de calle", utilizan la distinción Don / Mercancía para separar su "trabajo" de la práctica de "mendicidad", disputando el sentido mismo de su status social. Los autores señalan que el acento puesto en la "comercialización" y el "cambio" de un producto por dinero implica una estrategia para "des-marcarse" del estigma de ser categorizados bajo el universo de los "necesitados", fundamentalmente para aquellos vendedores que provenían de trayectorias de empleos estables y registrados y que, por el nuevo contexto socioeconómico, se encontraban desempleados (Wilkis \& Carenzo 2008, p. 166170). relación a la prestación económica: si bien no se construye en términos estrictos como una retribución, la prestación aparece justificada en torno a una actividad, un "hacer" que se constituye en relación al ingreso monetario en términos de merecimiento ${ }^{25}$. Esto funciona también como un punto problemático, en la medida en que esta intención de formación de criterios meritocráticos y de postura activa respecto del programa, se traduce luego en un desarreglo entre las expectativas (de los jóvenes) y las posibilidades reales (del programa y sus servicios).

\begin{abstract}
Hay chicos que vienen con un entusiasmo, porque como que en el POI se arma toda la historia de, de esto, de, que también como tutores hemos sido críticos muchas veces de lo que es el taller del POI; de la idea de esto de la voluntad, del mérito, del esfuerzo personal. Y entonces el joven sale muy entusiasmado, que va a venir al programa, va a conseguir una beca, una práctica laboral en una empresa, se va a insertar, y muchas veces no sucede esto (ET OE 8, 26.dez.2011).
\end{abstract}

El criterio de la empleabilidad vinculada al esfuerzo, y por lo tanto, la construcción de la práctica laboral (entrenamiento) en términos de práctica de rutinización y disciplina, apunta a la "promoción humana" y a la generación de sujetos "autónomos", rompiendo con la "dependencia" del Estado producto de las políticas asistencialistas.

\begin{abstract}
El programa se enmarca en la línea de políticas activas, digamos, intenta profundizar eso, que el joven haga una actividad y que por hacer la actividad cobre un incentivo, o sea, digamos, eso es lo que significa digamos, es lo que uno busca, es la autonomía del joven, digamos, y no la dependencia de un programa o de un beneficio, digamos, solamente, digamos, que se sostiene solamente por el beneficio, digamos, y que en realidad, que implica una actividad, digo, en sentido amplio, hacer una actividad implica la incorporación de valores, la incorporación de reglas, la incorporación de hábito de ir a trabajar, del hábito de estudiar, o sea, la posibilidad de generar relaciones, en ese sentido lo digo (ET OE 6, 14.set.2012).
\end{abstract}

De esta manera, la política activa define su propia alteridad, el asistencialismo, a partir de la recuperación de un criterio de funcionamiento del programa (el beneficio económico condicionado por una prestación o actividad dentro del mismo) en términos de valor para el trabajo, es decir, como mejoramiento de la empleabilidad del joven. El carácter activo se asocia a la idea de "esfuerzo" por parte de quien recibe el beneficio económico, y en este sentido, funciona como principal elemento de legitimación de una estrategia estatal que no se agota ya en una política de sostenimiento de ingresos.

\begin{abstract}
Ahí, el tema del jóvenes es como está diseñado y demás, la verdad que, dentro de las políticas, lo que yo valoro es que sea una política que vaya, que sea una política activa, o sea, no es una política pasiva que a todo el que esté inscripto se le dé una, una gratificación, un beneficio económico a fin de mes, si no que el joven ha demostrado, asistencia, participación en las distintas instancias, el joven va a recibir esta contraprestación a fin de mes en su cuenta personal. En ese sentido es un cambio para bien porque, digamos, (...) va mas a la promoción humana, y ahí el joven, como las tutoras, todo el equipo se le baja la línea diciendo: "Van a cobrar siempre y cuando cumplan al 100\% en esto", la empresa, digamos, no vas al día, nos reporta a nosotros y bueno: -"Joven, que pasó", -"No, bueno, no voy a ir mas". Al otro día se le da de baja entonces no cobra esa prestación, digamos, con esa cuestión remunerativa la manejamos como variable para tratar de, de fomentar esos hábitos de empleabilidad o como quieras llamarle (F OE 1, 10.set.2012).
\end{abstract}

\section{Reflexiones finales: lógicas políticas y culturales de gestión de la empleabilidad de jóvenes.}

El análisis de las lógicas político-institucionales como las racionalidades que operan tanto a nivel formal (la "letra", es decir, el dispositivo tal y cómo aparece estructurado) como informal (esto es, las definiciones propias de los 
agentes que lo ponen en funcionamiento) en las instancias gubernamentales de implementación del programa, implica el reconocimiento de una heterogeneidad significativa entre las distintas categorías de agentes que estudiamos. Aquí analizamos algunas lógicas generales y líneas de continuidad (reconstruidas analíticamente), y aunque no podamos desarrollarlo por cuestiones de espacio, debemos reconocer que existen diferencias importantes al interior de este grupo, no sólo en relación a trayectorias y formas de entendimiento y definición del programa, sino también (y fundamentalmente) a nivel de las condiciones desde las cuales estos agentes pueden ejercer sus prácticas, expuestos, sobre todo los integrantes del equipo técnico del nivel municipal, a una situación de fuerte inestabilidad y precariedad laboral. Este factor deberá ser profundizado para comprender este fenómeno en toda su complejidad.

A lo largo del escrito intentamos desarrollar algunos análisis que dieran lugar a conectar lo que entendemos como una gubernamentalidad propia del PJMyMT, articulada en torno al diagnóstico del problema del empleo para jóvenes "vulnerables", apoyado en producciones discursivas políticas y académicas, y su correlativa institucionalidad como lógica político-institucional localizada y territorializada.

En relación con estas dimensiones, en el marco de lo que se denominan "políticas activas" (y a la particular comprensión de esta dimensión que construyen los agentes gubernamentales), se define a la empleabilidad como objeto de intervención privilegiado de esta política, dando lugar a instancias y servicios estructurados en torno a lógicas de rutinización y disciplinamiento que orientan en este programa la producción de determinadas categorías de subjetividad para el trabajo. En este sentido, el PJMyMT se define en términos fuertemente pedagógicos. Esto refiere, antes que a un sentido de capacitación, a una noción de formación de disposiciones, hábitos y actitudes para el trabajo.

Esta lógica se inserta, tal como lo entendemos, en tanto intervención en la configuración de la "cultura del trabajo", en donde la estructuración del discurso de la empleabilidad en torno al valor del esfuerzo se sostiene en un esquema en el que, por un lado, esta cultura del trabajo como tradición y horizonte de significaciones aparece como un campo eficaz para la producción de legitimidad para las políticas públicas, y por lo tanto, para la construcción de procesos hegemónicos en torno a las contradictorias y complejas instancias estatales. Estos discursos aportan a la construcción de una lógica meritocrática como criterio de legitimación de la asignación de recursos (materiales y simbólicos), proceso que puede leerse como la persistencia de una concepción voluntarista de la acción (en este caso, de las prácticas laborales) y por lo tanto, como un elemento residual de la cosmovisión neoliberal con la cual el discurso de los agentes estatales pretenden romper y polemizar. El PJMyMT, en el marco de una configuración histórica de la cultura del trabajo, tiene la capacidad de plantear los límites de un campo de fuerzas aunque, por otra parte, no puede fijar los sentidos y las orientaciones de las disputas que aparecen en su interior. Reconocer los elementos residuales, las heterogeneidades, los sentidos en disputa, implica identificar los complejos intercambios entre los que, en la superficie del campo discursivo sobre el trabajo, aparecen como polos antagónicos: una cultura del trabajo post-convertibilidad en radical oposición a la "cultura de la dádiva estatal del neoliberalismo. 
Gonzalo Assusa (gon_assusa@hotmail.com) es Doctorando en Ciencias Antropológicas por la Universidad Nacional de Córdoba (UNC), Licenciado en Sociología por la Universidad Nacional de Villa María (UNVM), y Becario de Postrado de CONICET en el IDH-CONICET.

María Gabriela Brandán Zehnder (mgbrandanzehnder@gmail.com) es Doctoranda en Ciencia Política por la Universidad Nacional de Córdoba (UNC), Licenciada en Ciencia Política por la UCC, y Becario de Postrado de CONICET en la UCC. Docente en la UCC. Investigadora del Colectivo de Investigación El llano en llamas en la Universidad Católica de Córdoba Universidad Nacional de Córdoba (UCC-UNC).

\section{Referências}

Avalle, G. \& Brandán Zehnder, M.G., 2011. Entre la compensación y la inclusión. Tensiones en las políticas laborales y de empleo en la Argentina post-convertibilidad. Perspectivas de Políticas Públicas, 1(1), pp. 29-46.

Brandán Zehnder, M.G., 2011. ¿Empleables, para qué? Jóvenes e inclusión laboral en el marco del Programa Jóvenes con Más y Mejor Trabajo (PJMYMT). In $11^{\circ}$ Encuentro de Jóvenes Investigadores, Santiago.

Brandán Zehnder, M.G.; Hernández, J. \& Monte, E., 2010. Configurando desigualdades. El caso de dos políticas públicas en la Provincia de Córdoba (República Argentina): Programa Mejoramiento de Barrios (PROMEBA) y Programa de Inclusión Laboral Familia Joven. In III Congreso Uruguayo de Ciencia Política, Montevideo.

Brandan Zehnder, M.; De La Vega, C. \& Hernandez, J., 2012. Territorialidades manufacturadas: Lógicas político-institucionales y gestión del espacio. El caso PNDOT. Revista Escenarios, 19, pp. 102-115.

Castro, E., 2011. Diccionario Foucault. Temas, conceptos y autores. Buenos Aires: Siglo XXI.

Ciuffolini, M.A. \& Nuñez, A., eds. 2011. Política y territorialidad en tres ciudades argentinas. Buenos Aires: Ediciones El colectivo.

Foucault, M., 1983. El sujeto y el poder. In H.L. Dreyfus \& P. Rabinow, eds. Michel Foucault: más allá del estructuralismo y la hermeneútica. Buenos Aires:Ediciones Nueva Visión.

1992. Microfísica del poder. Madrid: Las ediciones de La Piqueta.

2004. Nacimiento de la biopolítica. Buenos Aires: Fondo de Cultura Económica.

2009. Seguridad, territorio y población: curso en el Collège de France 1977-1978. Buenos Aires: Fondo de Cultura Económica.

2010. Defender la sociedad. Buenos Aires: Fondo de Cultura Económica

Grassi, E. \& Danani, C., eds. 2009. El mundo del trabajo y los caminos de la vida: trabajar para vivir, vivir para trabajar. Buenos Aires: Espacio.

Jacinto, C.; Wolf, M.; Bessega, C. \& Longo, M.E., 2010. Jóvenes, precariedades y sentidos del trabajo. In VII Congreso Internacional de Estudios Sobre el Trabajo, Buenos Aires.

Jacinto, C., 2008. Los dispositivos recientes de empleo juvenil: institucionalidades, articulaciones con la educación formal y socialización laboral. Revista del Trabajo,4(6), pp. 123-142.

Jacinto, C. \& Millenaar, V., 2009. Enfoques de programas para la inclusión laboral de los jóvenes pobres: lo institucional como soporte subjetivo. Última década, 30, pp. 67-92.

. 2012. Los nuevos saberes para la inserción laboral. Formación para el trabajo con jóvenes vulnerables en Argentina. Revista Mexicana de Investigación Educativa,17(52), pp. 141-166.

Jardim, F.A.A., 2011. Chaves inúteis? Transformações nas culturas do trabalho e do emprego da perspectiva de experiências juvenis de desemprego por desalento. Estudos Sociológicos, 16(31), pp. 439-410.

Martín-Criado, E., 2005. La construcción de los problemas juveniles. Revista Nómadas, 23, pp. 86-93.

Merklen, D., 2005. Pobres ciudadanos. Las clases populares en la era democrática [Argentina 1983-2003]. Buenos Aires: Gorla.

Neffa, C., 2012. Empleo, desempleo y políticas de empleo. De las políticas pasivas a las políticas activas de empleo: análisis comparativo (1989-2011). Documento CEIL-PIETTE CONICET, 10, Segundo Trimestre.

Neffa, C. \& Panigo, D., 2009. El mercado de trabajo argentino en el nuevo modelo de desarrollo. Dirección Nacional de Programación Macroeconómica. Dirección de Modelos y 9 Proyecciones. Buenos Aires: Ministerio de Economía y Finanzas Públicas de Nación.

Neffa, J., 2008. Políticas de empleo y políticas sociales: ¿complementariedad o contradicción? In A. Heras \& D. Burin, eds. 2008. Trabajo, Desarrollo y Diversidad: políticas y metodologías de desarrollo local con acento en la creación de empleo, trabajo e ingresos. Buenos Aires: INCLUIR-CICCUS.

Palenzuela Palencia, P., 1995. Las culturas del trabajo. Una aproximación antropológica. Sociología del Trabajo, 24, pp. 328.

Piñuel Raigada, J.L., 2002. Epistemología, metodología y técnicas de análisis de contenido. Revista Estudios de Sociolingüística, 3(1), pp. 1-42.

Rosanvallon, P., 2007. La nueva cuestión social: repensar el Estado providencia. Buenos Aires: Manantial. 
Salvia, A., ed. 2008. Jóvenes promesas. Trabajo, educación y exclusión social de jóvenes pobres en la Argentina. Buenos Aires: Universidad de Buenos Aires.

Shore, C., 2010. La antropología y el estudio de la política pública: reflexiones sobre la "formulación” de las políticas. Antípoda, 10, pp. 21-49,

Wilkis, A. \& Carenzo, S., 2008. Lidiar con dones, lidiar con mercancías. Etnografías de transacciones económicas y morales. Apuntes de Investigación del CECYP,14, pp. 159-193.

\begin{abstract}
The aim of this article is to analyze how political and institutional logics associated with management and production of youth employment, work. We assume that these government interventions are designed attending mainly to employability and, moreover, they contribute to shape work culture. We analyze the case of a youth employment policy named Programa Jóvenes con Más y Mejor Trabajo (PJMyMT ), implemented by the Ministerio de Trabajo, Empleo y Seguridad Social de la Nación ( MTEySS ), in Córdoba, Argentina. To seek our aims, we use a technique of gathering qualitative data from interviews with both members of the technical staff from PJMyMT and government employees from the MTEySS, during the years 2011 and 2012. Here we explored the meanings they've create around the diagnosis of youth unemployment, the place that the state should have related to it and the particular type of intervention that is proposed from the notion of employability, in the context of active employment policies. We used to process data, the strategy of content analysis. The study we've made over the political and institutional logic, allowed to reconstruct the senses built by agents that implement it and also, the practices that the device leads. Thus, a first conclusion realizes that "employability " is defined as a privileged object of intervention of this state program, leading to instances around logics of routinization and discipline oriented to the production of certain categories of subjectivity around work. In this sense, the PJMyMT is defined in terms of pedagogical strategies focused on training layouts, habits and attitudes to work, rather than strictly a function trainer. Thus, the second conclusion is that this logic is inserted, as we understand it, as an intervention in the setting of the work culture in which the discourse of employability is structured around the value of effort and held over a scheme in which the work culture and tradition emerges as horizon of meanings, appearing as an effective field production of legitimacy for public policies. Finally, we understand that these discourses contribute to build a meritocratic logic and legitimacy criterion for the allocation of state resources, a process that can be read as the persistence of a voluntarism conception of labor practices and as a residual element of the neoliberal worldview, which agents and officials seek to argue. The results of this article are oriented to open a debate in the analysis of the youth labor market devices, to separate ourselves analytically from an institutionalism view of government programs in order to understand, instead, the effects of power that they produce in their recipients.
\end{abstract}

KEYWORDS: work; youth; employability; governmentality; work culture 